\title{
Recent Advances in the Treatment of Mucormycosis
}

\author{
Brad Spellberg • Ashraf S. Ibrahim
}

Published online: 10 August 2010

(C) The Author(s) 2010. This article is published with open access at Springerlink.com

\begin{abstract}
In recent years, substantial advances have been achieved in the treatment of mucormycosis. It is now clear that early initiation of therapy results in substantially better outcomes, underscoring the need to maintain a high index of suspicion and aggressively biopsy potential lesions. Increasing data support the need for surgical excision of infected and/or necrosed tissue whenever feasible. Based on their superior safety and efficacy, lipid formulations of amphotericin B have become the standard treatment for mucormycosis. Posaconazole may be useful as salvage therapy, but cannot be recommended as primary therapy for mucormycosis based on available data. Pre-clinical and limited retrospective clinical data suggest that combination therapy with lipid formulations of amphotericin and an echinocandin improves survival during mucormycosis. A definitive trial is needed to confirm these results. The use of the iron chelator, deferasirox, as adjunctive therapy also improved outcomes in animal models of mucormycosis. However, its efficacy was not confirmed in a recent, phase 2 clinical trial. Additional study is required of the potential for abrogation of iron acquisition as adjunctive treatment of
\end{abstract}

\footnotetext{
B. Spellberg

The Division of General Internal Medicine, Los Angeles Biomedical Research Institute at Harbor-University of California at Los Angeles (UCLA) Medical Center,

1124 West Carson Street,

Torrance, CA 90502, USA

B. Spellberg $(\bowtie) \cdot$ A. S. Ibrahim

The David Geffen School of Medicine at UCLA,

Los Angeles, CA, USA

e-mail: bspellberg@labiomed.org

A. S. Ibrahim

The Division of Infectious Diseases, Harbor-UCLA Medical Center,

West Carson, CA, USA
}

mucormycosis. Combination polyene-posaconazole therapy was of no benefit in pre-clinical studies. Adjunctive therapy with recombinant cytokines, hyperbaric oxygen, and/or granulocyte transfusions can be considered in selected patients. Large-scale, prospective, randomized clinical trials are needed to define optimal management strategies for mucormycosis.

Keywords Mucormycosis · Amphotericin · Liposomal amphotericin · Amphotericin B lipid complex .

Posaconazole $\cdot$ Echinocandins $\cdot$ Deferasirox

\section{Introduction}

Mucormycosis is a life-threatening infection caused by fungi of the order Mucorales. Recent re-classification has abolished the class Zygomycetes and placed the order Mucorales in the subphylum Mucormycotina [1]. Therefore, we refer to infection caused by Mucorales as mucormycosis rather than zygomycosis.

Mucormycosis typically occurs in patients with diabetes mellitus, organ or hematopoietic stem cell transplantation (HSCT), neutropenia, or malignancy $[2,3]$. The incidence of mucormycosis appears to be increasing, based on data from cancer centers in the United States and Europe [2, 48] and PubMed publications [9]. Furthermore, a recent, comprehensive, population-based epidemiology study found a near doubling of the frequency of mucormycosis cases throughout France over a 10-year period (1997-2006) [10].

For decades, the mortality rate of mucormycosis has remained $\geq 40 \%$ despite aggressive surgical and antifungal therapy [2, 3, 7, 11-14]. In patients with hematologic malignancy or HSCT, mortality rates exceed $65 \%$ and $90 \%$, 
respectively. Mortality rates exceed $65 \%$ in patients with hematologic malignancy, and in those with HSCT, mortality rates exceed $90 \%$. However, recent translational research, funded by the US National Institutes of Health and by the pharmaceutical industry, has resulted in several new treatment strategies for mucormycosis, raising the possibility of improving outcomes based on superior medical therapy.

\section{Background Treatment Strategies for Mucormycosis}

The successful treatment of mucormycosis requires four steps: 1) early diagnosis; 2) reversal of underlying predisposing risk factors, if possible; 3) surgical debridement where applicable; and 4) prompt antifungal therapy [3].

\section{Early Diagnosis}

A recent study from Chamilos et al. [15••] quantified the benefit of early initiation of polyene antifungal therapy. They reported that if treatment was initiated within 5 days of diagnosis of mucormycosis, survival was markedly improved compared to initiation of polyene therapy at $\geq 6$ days after diagnosis ( $83 \%$ vs $49 \%$ survival). Hence, establishing an early diagnosis of mucormycosis is critical to enable early initiation of active antifungal therapy.

The development of other diagnostic methods is a major unmet need for this infection. Development of quantitative polymerase chain reaction systems is a promising area of ongoing research to enable more rapid diagnosis [16-19]. The most common finding by CT scanning of patients with rhino-orbital-cerebral disease is simply sinusitis, so absence of deeper infection by CT scan does not rule out mucormycosis [20•*]. MRIs are more sensitive than CT scans for detecting orbital and central nervous system (CNS) involvement $[20 \bullet$. CT scans are useful for early detection of pulmonary mucormycosis, particularly in patients with cancer. By logistic regression, pulmonary mucormycosis in patients with cancer could be distinguished from aspergillosis on the basis of sinusitis, presence of multiple $(\geq 10)$ nodules by CT scan, and pleural effusion [21].

\section{Reversal of Underlying Disease}

It is critical to reverse/prevent underlying defects in host defense when treating patients with mucormycosis. Immunosuppressive medications, particularly corticosteroids, should be dose reduced or stopped if at all possible. Aggressive management to rapidly restore euglycemia and normal acidbase status is critical in diabetic patients in ketoacidosis. Administration of iron should be avoided, because it exacerbates the severity of infection in animal models of mucormycosis $[22,23,24 \bullet \bullet]$. For the same reason, it may be advisable to minimize blood transfusions, if feasible.

\section{Surgical Management}

Blood vessel thrombosis and resulting tissue necrosis during mucormycosis can result in poor penetration of antifungal agents to the site of infection. Therefore, debridement of necrotic tissues may be critical for complete eradication of mucormycosis. In a recent study, surgery was found to be an independent variable by logistic regression for favorable outcome in patients with mucormycosis [2]. Furthermore, in multiple case series, patients who did not undergo surgical debridement of mucormycosis had a far higher mortality rate than patients who underwent surgery $[5,25-32]$. Although there is potential selection bias in these case series, as patients who did not undergo surgery likely differed in disease severity or comorbidities from those who did, these data support the concept that surgical debridement is necessary to optimize cure rates.

The extent and timing of surgical debridement necessary to maximize outcomes of mucormycosis has never been defined. Data from a recent retrospective review of patients with rhino-orbital-cerebral mucormycosis [20••] support the use of intraoperative frozen sections to delineate the margins of infected tissues so that uninvolved tissues can be spared from debridement. The use of calcofluor fluorescence microscopy has also been reported to increase the sensitivity of frozen sections for guiding extent of surgical revision [33].

\section{Antifungal Therapy}

\section{First-Line Monotherapy Options}

In general, primary antifungal therapy for mucormycosis should be based on a polyene, if possible. Although amphotericin $\mathrm{B}$ deoxycholate $(\mathrm{AmB})$ was the cornerstone of mucormycosis therapy for decades, lipid formulations of AmB are significantly less nephrotoxic and can be safely administered at higher doses for a longer period of time than $\mathrm{AmB}[20 \bullet \bullet, 34]$. Furthermore, treatment of mucormycosis with liposomal amphotericin B (LAmB) was associated with a $67 \%$ survival rate, compared to $39 \%$ survival when patients were treated with $\mathrm{AmB}(p=0.02)$ [9]. Multiple other, more recent case series also found initial therapy with LAmB to be substantially more effective than other options $[13,35,36]$. Therefore, most experts now prefer to use lipid polyenes rather than $\mathrm{AmB}$ for the treatment of mucormycosis.

Available data indicate advantages of LAmB over amphotericin B lipid complex (ABLC) for the treatment 
of CNS mucormycosis. For example, LAmB levels achieved in rabbit brain were fivefold above ABLC levels [37]. Furthermore, while similarly effective in neutropenic mice, LAmB was markedly superior to ABLC in diabetic ketoacidotic (DKA) mice infected with Rhizopus oryzae, primarily because of superior clearance of fungus from the brain [38]. These animal studies are complemented by a recent, relatively small retrospective case series, in which the outcomes of patients with rhino-orbital-cerebral mucormycosis were found to be worse when ABLC was used as initial therapy versus AmB or LAmB [20••].

In contrast, a recent murine study found that ABLC achieves superior lung levels than LAmB, resulting in superior clearance of fungus from the lungs [39]. When a higher dose of LAmB was used than ABLC, the efficacy was similar. No clinical studies are available yet to validate these intriguing murine data.

In the absence of definitive data on dose selection, 5$7.5 \mathrm{mg} / \mathrm{kg} / \mathrm{d}$ of lipid polyenes are reasonable for most cases of mucormycosis. A recent randomized study of 339 patients with various mold infections found no clinical benefit of LAmB dosed at $10 \mathrm{mg} / \mathrm{kg} / \mathrm{d}$ versus $3 \mathrm{mg} / \mathrm{kg} / \mathrm{d}$ [40]. However, there were only five total cases of mucormycosis in the study, none of which involved the CNS. Given the low CNS penetration of polyenes, some experts prefer dose escalation to $10 \mathrm{mg} / \mathrm{kg} / \mathrm{d}$ of LAmB for CNS mucormycosis. Higher doses of LAmB do not result in pharmacokinetic advantage compared to $10 \mathrm{mg} / \mathrm{kg} / \mathrm{d}$ [41].

Fluconazole, voriconazole, and itraconazole do not have reliable activity against mucormycosis [42-52]. The reported in vitro minimum inhibitory concentration for $90 \%$ of organisms $\left(\mathrm{MIC}_{90}\right)$ of posaconazole against the Mucormycotina has ranged from $1 \mu \mathrm{g} / \mathrm{mL}$ to $\geq 4 \mu \mathrm{g} / \mathrm{mL}$ [42, 53-56]. However, in patients with febrile neutropenia or invasive fungal infections, posaconazole dosed at $400 \mathrm{mg}$ twice daily resulted in serum levels less than $1 \mu \mathrm{g} / \mathrm{mL}$, with considerable variability [57-59]. These data raise concerns about the reliability of achieving adequate in vivo levels of posaconazole to treat mucormycosis. Furthermore, posaconazole is relatively ineffective for the treatment of mucormycosis in pre-clinical animal models [50, 60-62]. The efficacy of posaconazole as a treatment option is further called into question by reports of mucormycosis developing as a breakthrough infection while on posaconazole prophylaxis [63-65]. Thus, posaconazole cannot be recommended as a first-line treatment for mucormycosis.

In contrast, van Burik et al. [66] reported 60\% response rates (45\% partial response, $15 \%$ complete response) for salvage therapy in patients with mucormycosis who were refractory to or intolerant of polyenes. Greenberg et al. [67] reported similar results. Hence, posaconazole is an option for salvage therapy for these infections.
Combination Antifungal Therapy for Mucormycosis

It is now known that $R$. oryzae expresses the target enzyme for echinocandins [68]. In DKA mice infected with $R$. oryzae, combination caspofungin plus ABLC therapy markedly improved survival compared to either monotherapy or placebo [69]. Combination therapy with LAmB plus either micafungin or anidulafungin was also synergistic in either neutropenic or DKA mice with disseminated mucormycosis [70].

In a recent retrospective review from two institutions, combination polyene-caspofungin therapy was associated with significantly improved outcomes in patients with rhino-orbital and rhino-orbital-cerebral mucormycosis compared to polyene monotherapy [20••]. Most of the patients were diabetic, although some patients in the series had neutropenia or were solid-organ transplant recipients. In multivariate analysis, only combination therapy was significantly associated with superior outcomes $(\mathrm{OR}=$ 10.9 for success vs monotherapy, $p=0.02$ ).

Echinocandins have extremely favorable toxicity profiles. Furthermore, at an average hospitalization cost of $\sim \$ 100,000$ per case of mucormycosis [71], addition of an echinocandin at $\sim \$ 100$ per day for 2-4 weeks would increase hospital costs by a small amount (ie, $<3 \%$ ). Thus, neither toxicity nor cost is a compelling reason to avoid combination polyeneechinocandin therapy for patients with mucormycosis. If used as combination therapy, echinocandins should be administered at standard doses-dose escalation is not recommended, due to paradoxical loss of efficacy during murine mucormycosis at doses $\geq 3 \mathrm{mg} / \mathrm{kg} / \mathrm{d}[68,70]$. A largescale, definitive, phase 3 clinical trial is necessary to determine if combination lipid polyene-echinocandin therapy is superior to monotherapy.

The central role of iron in pathogenesis of mucormycosis has been confirmed based on in vitro and in vivo animal models, and retrospective human studies [22, 23, 24・•, 72 $75,76 \bullet \bullet$. The requirement for iron acquisition for $R$. oryzae growth and pathogenesis suggested that abrogation of iron uptake could be an important therapeutic adjunct for mucormycosis infections. Indeed, the iron chelators deferiprone and deferasirox, the latter of which is approved by the US Food and Drug Administration to treat iron overload in transfusion-dependent anemias [77], improved survival in rodents with mucormycosis [24••, 72, 74]. Deferasirox was cidal for 28 of 29 clinical isolates of Mucormycotina in vitro, with an $\mathrm{MIC}_{90}$ of $6.25 \mu \mathrm{g} / \mathrm{mL}$ [34••]. The drug exhibited time-dependent killing, with cidality occurring at 12-24 h of drug exposure. Based on trough serum levels of greater than $15 \mu \mathrm{g} / \mathrm{mL}$ in patients treated with deferasirox at $20 \mathrm{mg} / \mathrm{kg} / \mathrm{d}$, it should be feasible to maintain serum levels in excess of the MICs of Mucormycotina throughout the entire dosing interval [78, 79]. 
In mice with disseminated mucormycosis, deferasirox was as effective as LAmB therapy, and combination deferasiroxLAmB therapy synergistically improved survival $(80 \%$ survival for combination vs $40 \%$ for either monotherapy vs $0 \%$ for placebo) $[24 \bullet \cdot]$. In particular, combination therapy resulted in a 100-fold decrease in brain fungal burden compared to monotherapy. Based on these animal data, deferasirox has been used off label as adjunctive therapy for mucormycosis patients, both when it was the first agent prescribed temporally and in salvage situations [80, 81]. Although limited open-label clinical experience has not revealed substantial toxicity of the addition of deferasirox to a polyene or posaconazole-based backbone regimen, a recently completed phase 2, double-blind, randomized, placebo-controlled trial of adjunctive deferasirox therapy failed to demonstrate a benefit of the combination regimen in patients with mucormycosis.

The toxicities of deferasirox therapy in nonhuman primates and in clinical trials have been extensively reviewed [77, 82, 83], and are beyond the scope of the current article. However, the primary toxicity of concern for the treatment of mucormycosis is renal failure. Elevations in creatinine occurred in up to one third of patients in deferasirox clinical trials [82, 84], but were usually mild and almost always reversible upon cessation of the drug. There have been rare, postmarketing reports of severe acute renal failure resulting in hemodialysis or death in patients taking deferasirox [85]. However, these patients typically had other underlying risk factors for renal failure. Therefore, the contribution of deferasirox to the renal failure in these cases is unclear. Until more data are available, deferasirox should be used cautiously in the setting of mucormycosis, as toxicities are not well characterized.

No clinical data exist to address the role of combination posaconazole-polyene therapy for mucormycosis. However, two recent pre-clinical studies evaluated the efficacy of posaconazole combination therapy during murine mucormycosis. In the first study, Rodriguez et al. [61] found that combining posaconazole with $\mathrm{AmB}$ enhanced the survival of neutropenic mice infected with $R$. oryzae only when compared to a subtherapeutic dose of $\mathrm{AmB}$ monotherapy $(0.3 \mathrm{mg} / \mathrm{kg} / \mathrm{d})$. In contrast, combination therapy was of no advantage compared to AmB monotherapy at a standard dose $(0.8 \mathrm{mg} / \mathrm{kg} / \mathrm{d})$. Similarly, we recently reported that combination posaconazole plus LAmB was of no benefit compared to monotherapy with LAmB alone in either neutropenic or DKA mice with mucormycosis [62]. Based on available data, posaconazole does not have a clear role as adjunctive therapy in combination with lipid polyenes.

Ben-Ami et al. [86] recently reported that the antibacterial agent, colistin, has activity against the Mucorales. Colistin was cidal in vitro, although regrowth of the fungus occurred unless subinhibitory AmB was added for synergy. Colistin's mechanism of action appeared to involve disruption of the cytoplasmic and intracellular vacuolar membrane integrity. The drug had limited activity as a prophylactic agent during inhalational challenge, but did not have systemic therapeutic activity. Its potential role as a second agent in a combination regimen merits further study.

Proinflammatory cytokines, such as interferon (IFN)- $\gamma$ and granulocyte-macrophage colony-stimulating factor (GM-CSF), enhance the ability of granulocytes to damage the agents of mucormycosis [87]. Adjunctive immune therapy with recombinant granulocyte colony-stimulating factor (G-CSF) and GM-CSF, or with recombinant IFN- $\gamma$, has been used successfully in conjunction with lipid formulations of amphotericin B in treatment of mucormycosis [88-90]. Whether recombinant cytokines have a role in the primary treatment of mucormycosis in immunocompromised patients is not well-defined.

G-CSF-mobilized granulocyte transfusions have been increasingly used for refractory mycoses, including mucormycosis [91]. Although the reported experience in management of mucormycosis with granulocyte transfusions is limited, such transfusions use may contain the infection and be life-saving in persistently neutropenic hosts with this infection. Finally, based on limited experimental and clinical data, hyperbaric oxygen therapy may be also useful in centers with the appropriate technical expertise and facilities [92].

\section{Salvage Therapy}

Posaconazole or deferasirox are reasonable salvage options for patients with mucormycosis refractory to or intolerant of polyene therapy. Substantially more clinical data are available for posaconazole in this setting [66, 67]. Posaconazole appears to be quite safe despite dosing for months to years of administration [66, 67].

Experience is limited with deferasirox as salvage therapy. However, in case series and case reports, its addition to patients progressing on previous therapy has resulted in favorable outcomes without substantive toxicity $[80,86$, 93]. If deferasirox is used, it should be used cautiously and with regular monitoring of renal and hepatic function. Administration at a dose of $20 \mathrm{mg} / \mathrm{kg} / \mathrm{d}$ for $2-4$ weeks is reasonable for salvage therapy, because in pre-clinical studies of non-iron-overloaded primates, deferasirox toxicity increased beyond 4 weeks of therapy [83].

G-CSF-mobilized granulocyte transfusions may provide additional support for persistently neutropenic patients until recovery from neutropenia. Administration of GM-CSF or IFN- $\gamma$ may further augment host response and antifungal effect in non-neutropenic patients with refractory infection. In a recent murine study, addition to LAmB therapy of GM- 
CSF, but not IFN- $\gamma$, improved the survival of mice with mucormycosis [94].

\section{Conclusions}

In recent years, numerous new options for the treatment of mucormycosis have become available. Lipid formulations of amphotericin are currently the preferred first-line treatment for mucormycosis, with a possible preference for liposomal amphotericin for CNS infection. The possibility of combination therapy with lipid amphotericin B and an echinocandins or iron-blocking strategy merits additional investigation. Salvage therapy options are numerous, including posaconazole, deferasirox, adjunctive cytokine therapy, and hyperbaric oxygen. Underlying all successful antifungal use is the need to reverse underlying host defects predisposing to infection, surgically debride necrotic tissue whenever possible, and make an early diagnosis to facilitate rapid initiation of antifungal therapy.

Acknowledgments Some of the research discussed in this review was supported by Public Health Service grants K08 to BJS, and R01 AI063503 and R21 AI064716 to ASI.

Disclosure Dr. Spellberg has received consulting fees from Pfizer, Astellas, Basilea, Merck, Achaogen, Trius, and Novartis, and grant research support from Astellas, Gilead, and Novartis.

Dr. Ibrahim has received research funding from Astellas, Enzon, Gilead, Merck, Elan, Novartis, and Pfizer, and speaker's honoraria from Astellas.

Open Access This article is distributed under the terms of the Creative Commons Attribution Noncommercial License which permits any noncommercial use, distribution, and reproduction in any medium, provided the original author(s) and source are credited.

\section{References}

Papers of particular interest, published recently, have been highlighted as:

•• Of major importance

1. Hibbett DS, Binder M, Bischoff JF, et al.: A higher-level phylogenetic classification of the fungi. Mycol Res 2007, 111:509-547.

2. Roden MM, Zaoutis TE, Buchanan WL, et al.: Epidemiology and outcome of zygomycosis: a review of 929 reported cases. Clin Infect Dis 2005, 41:634-653.

3. Spellberg B, Edwards J Jr, Ibrahim A: Novel perspectives on mucormycosis: pathophysiology, presentation, and management. Clin Microbiol Rev 2005, 18:556-569.

4. Kontoyiannis DP, Lionakis MS, Lewis RE, et al.: Zygomycosis in a tertiary-care cancer center in the era of Aspergillus-active antifungal therapy: a case-control observational study of 27 recent cases. J Infect Dis 2005, 191:1350-1360.
5. Kontoyiannis DP, Wessel VC, Bodey GP, Rolston KV: Zygomycosis in the 1990s in a tertiary-care cancer center. Clin Infect Dis 2000, 30:851-856.

6. Marr KA, Carter RA, Crippa F, et al.: Epidemiology and outcome of mould infections in hematopoietic stem cell transplant recipients. Clin Infect Dis 2002, 34:909-917.

7. Saegeman V, Maertens J, Ectors N, et al.: Epidemiology of mucormycosis: review of 18 cases in a tertiary care hospital. Med Mycol 2010, 48:245-254.

8. Ambrosioni J, Bouchuiguir-Wafa $\mathrm{K}$, Garbino J: Emerging invasive zygomycosis in a tertiary care center: epidemiology and associated risk factors. Int J Infect Dis 2010 (Epub ahead of print).

9. Gleissner B, Schilling A, Anagnostopolous I, et al.: Improved outcome of zygomycosis in patients with hematological diseases? Leuk Lymphoma 2004, 45:1351-1360.

10. Bitar D, Van Cauteren D, Lanternier F, et al.: Increasing incidence of zygomycosis (mucormycosis), France, 1997-2006. Emerg Infect Dis 2009, 15:1395-1401.

11. Ribes JA, Vanover-Sams CL, Baker DJ: Zygomycetes in human disease. Clin Microbiol Rev 2000, 13:236-301.

12. Neofytos D, Horn D, Anaissie E, et al.: Epidemiology and outcome of invasive fungal infection in adult hematopoietic stem cell transplant recipients: analysis of Multicenter Prospective Antifungal Therapy (PATH) Alliance registry. Clin Infect Dis 2009, 48:265-273.

13. Ruping MJ, Heinz WJ, Kindo AJ, et al.: Forty-one recent cases of invasive zygomycosis from a global clinical registry. J Antimicrob Chemother 2010, 65:296-302.

14. Sun HY, Aguado JM, Bonatti H, et al.: Pulmonary zygomycosis in solid organ transplant recipients in the current era. Am J Transplant 2009, 9:2166-2171.

15. • Chamilos G, Lewis RE, Kontoyiannis DP: Delaying amphotericin B-based frontline therapy significantly increases mortality among patients with hematologic malignancy who have zygomycosis. Clin Infect Dis 2008, 47:503-509. This article describes a very compelling study precisely defining the necessary timing of initiation of therapy for mucormycosis to maximize outcomes in the cancer setting.

16. Francesconi A, Kasai M, Harrington SM, et al.: Automated and manual methods of DNA extraction for Aspergillus fumigatus and Rhizopus oryzae analyzed by quantitative real-time PCR. J Clin Microbiol 2008, 46:1978-1984.

17. Hata DJ, Buckwalter SP, Pritt BS, et al.: Real-time PCR method for detection of zygomycetes. J Clin Microbiol 2008, 46:23532358.

18. Kasai M, Harrington SM, Francesconi A, et al.: Detection of a molecular biomarker for zygomycetes by quantitative PCR assays of plasma, bronchoalveolar lavage, and lung tissue in a rabbit model of experimental pulmonary zygomycosis. J Clin Microbiol 2008, 46:3690-3702.

19. Dannaoui E, Schwarz P, Slany M, et al.: Molecular detection and identification of zygomycetes species from paraffinembedded tissues in a murine model of disseminated zygomycosis: a collaborative European Society of Clinical Microbiology and Infectious Diseases (ESCMID) Fungal Infection Study Group (EFISG) evaluation. J Clin Microbiol 2010, 48:20432046.

20. • Reed C, Bryant R, Ibrahim AS, et al.: Combination polyenecaspofungin treatment of rhino-orbital-cerebral mucormycosis. Clin Infect Dis 2008, 47:364-371. This retrospective study describes superior outcomes in patients with mucormycosis treated with combination polyene-echinocandin therapy.

21. Chamilos G, Marom EM, Lewis RE, et al.: Predictors of pulmonary zygomycosis versus invasive pulmonary aspergillosis in patients with cancer. Clin Infect Dis 2005, 41:60-66. 
22. Boelaert JR, de Locht M, Van Cutsem J, et al.: Mucormycosis during deferoxamine therapy is a siderophore-mediated infection. In vitro and in vivo animal studies. J Clin Invest 1993, 91:19791986.

23. Van Cutsem J, Boelaert JR: Effects of deferoxamine, feroxamine and iron on experimental mucormycosis (zygomycosis). Kidney Int 1989, 36:1061-1068.

24. •- Ibrahim AS, Gebermariam T, Fu Y, et al:: The iron chelator deferasirox protects mice from mucormycosis through iron starvation. J Clin Invest 2007, 117:2649-2657. This seminal study defines the potential for iron chelation to serve as synergistic, adjunctive therapy for mucormycosis.

25. Nithyanandam S, Jacob MS, Battu RR, et al.: Rhino-orbitocerebral mucormycosis. A retrospective analysis of clinical features and treatment outcomes. Indian J Ophthalmol 2003, 51:231-236.

26. Peterson KL, Wang M, Canalis RF, Abemayor E: Rhinocerebral mucormycosis: evolution of the disease and treatment options. Laryngoscope 1997, 107:855-862.

27. Khor BS, Lee MH, Leu HS, Liu JW: Rhinocerebral mucormycosis in Taiwan. J Microbiol Immunol Infect 2003, 36:266-269.

28. Petrikkos G, Skiada A, Sambatakou H, et al.: Mucormycosis: tenyear experience at a tertiary-care center in Greece. Eur J Clin Microbiol Infect Dis 2003, 22:753-756.

29. Tedder M, Spratt JA, Anstadt MP, et al.: Pulmonary mucormycosis: results of medical and surgical therapy. Ann Thorac Surg 1994, 57:1044-1050.

30. Pavie J, Lafaurie M, Lacroix C, et al.: Successful treatment of pulmonary mucormycosis in an allogenic bone-marrow transplant recipient with combined medical and surgical therapy. Scand J Infect Dis 2004, 36:767-769.

31. Reid VJ, Solnik DL, Daskalakis T, Sheka KP: Management of bronchovascular mucormycosis in a diabetic: a surgical success. Ann Thorac Surg 2004, 78:1449-1451.

32. Asai K, Suzuki K, Takahashi T, et al.: Pulmonary resection with chest wall removal and reconstruction for invasive pulmonary mucormycosis during antileukemia chemotherapy. Jpn J Thorac Cardiovasc Surg 2003, 51:163-166.

33. McDermott NE, Barrett J, Hipp J, et al.: Successful treatment of periodontal mucormycosis: report of a case and literature review. Oral Surg Oral Med Oral Pathol Oral Radiol Endod 2010, 109: e64-e69.

34. Walsh TJ, Hiemenz JW, Seibel NL, et al.: Amphotericin B lipid complex for invasive fungal infections: analysis of safety and efficacy in 556 cases. Clin Infect Dis 1998, 26:1383-1396.

35. Pagano L, Valentini CG, Posteraro B, et al.: Zygomycosis in Italy: a survey of FIMUA-ECMM (Federazione Italiana di Micopatologia Umana ed Animale and European Confederation of Medical Mycology). J Chemother 2009, 21:322-329.

36. Singh N, Aguado JM, Bonatti $\mathrm{H}$, et al.: Zygomycosis in solid organ transplant recipients: a prospective, matched case-control study to assess risks for disease and outcome. J Infect Dis 2009, 200:1002-1011.

37. Groll AH, Giri N, Petraitis V, et al.: Comparative efficacy and distribution of lipid formulations of amphotericin B in experimental Candida albicans infection of the central nervous system. J Infect Dis 2000, 182:274-282.

38. Ibrahim AS, Gebremariam T, Husseiny MI, et al.: Comparison of lipid amphotericin B preparations in treating murine zygomycosis. Antimicrob Agents Chemother 2008, 52:15731576.

39. Lewis RE, Liao G, Hou J, et al.: Comparative analysis of amphotericin B lipid complex and liposomal amphotericin B kinetics of lung accumulation and fungal clearance in a murine model of acute invasive pulmonary aspergillosis. Antimicrob Agents Chemother 2007, 51:1253-1258.
40. Cornely OA, Maertens J, Bresnik M, et al.: Liposomal amphotericin $\mathrm{B}$ as initial therapy for invasive mold infection: a randomized trial comparing a high-loading dose regimen with standard dosing (AmBiLoad trial). Clin Infect Dis 2007, 44:1289-1297.

41. Walsh TJ, Goodman JL, Pappas P, et al.: Safety, tolerance, and pharmacokinetics of high-dose liposomal amphotericin B (AmBisome) in patients infected with Aspergillus species and other filamentous fungi: maximum tolerated dose study. Antimicrob Agents Chemother 2001, 45:3487-3496.

42. Sun QN, Fothergill AW, McCarthy DI, et al.: In vitro activities of posaconazole, itraconazole, voriconazole, amphotericin $\mathrm{B}$, and fluconazole against 37 clinical isolates of zygomycetes. Antimicrob Agents Chemother 2002, 46:1581-1582.

43. Trifilio SM, Bennett CL, Yarnold PR, et al.: Breakthrough zygomycosis after voriconazole administration among patients with hematologic malignancies who receive hematopoietic stem-cell transplants or intensive chemotherapy. Bone Marrow Transplant 2007, 39:425-429.

44. Marty FM, Cosimi LA, Baden LR: Breakthrough zygomycosis after voriconazole treatment in recipients of hematopoietic stemcell transplants. N Engl J Med 2004, 350:950-952.

45. Kauffman CA: Zygomycosis: reemergence of an old pathogen. Clin Infect Dis 2004, 39:588-590.

46. Imhof A, Balajee SA, Fredricks DN, et al.: Breakthrough fungal infections in stem cell transplant recipients receiving voriconazole. Clin Infect Dis 2004, 39:743-746.

47. Ide L, Buysschaert I, Demuynck H, et al.: Zygomycosis in neutropenic patients with past Aspergillus infection: a role for posaconazole? Clin Microbiol Infect 2004, 10:862-863.

48. Vigouroux S, Morin O, Moreau P, et al.: Zygomycosis after prolonged use of voriconazole in immunocompromised patients with hematologic disease: attention required. Clin Infect Dis 2005, 40:e35-e37.

49. Rickerts V, Böhme A, Just-Nübling G: Risk factor for invasive zygomycosis in patients with hematologic malignancies [in German]. Mycoses 2002, 45(Suppl 1):27-30.

50. Dannaoui E, Meis JF, Loebenberg D, Verweij PE: Activity of posaconazole in treatment of experimental disseminated zygomycosis. Antimicrob Agents Chemother 2003, 47:3647-3650.

51. Dannaoui E, Meletiadis J, Mouton JW, et al.: In vitro susceptibilities of zygomycetes to conventional and new antifungals. J Antimicrob Chemother 2003, 51:45-52.

52. Van Cutsem J, Van Gerven F, Fransen J, Janssen PA: Treatment of experimental zygomycosis in guinea pigs with azoles and with amphotericin B. Chemotherapy 1989, 35:267272.

53. Pfaller MA, Messer SA, Hollis RJ, Jones RN: Antifungal activities of posaconazole, ravuconazole, and voriconazole compared to those of itraconazole and amphotericin B against 239 clinical isolates of Aspergillus spp. and other filamentous fungi: report from SENTRY Antimicrobial Surveillance Program, 2000. Antimicrob Agents Chemother 2002, 46:1032-1037.

54. Almyroudis NG, Sutton DA, Fothergill AW, et al.: In vitro susceptibilities of 217 clinical isolates of zygomycetes to conventional and new antifungal agents. Antimicrob Agents Chemother 2007, 51:2587-2590.

55. Lass-Flörl C, Mayr A, Perkhofer S, et al.: Activities of antifungal agents against yeasts and filamentous fungi: assessment according to the methodology of the European Committee on Antimicrobial Susceptibility Testing. Antimicrob Agents Chemother 2008, 52:3637-3641.

56. Arikan S, Sancak B, Alp S, et al.: Comparative in vitro activities of posaconazole, voriconazole, itraconazole, and amphotericin B against Aspergillus and Rhizopus, and synergy testing for Rhizopus. Med Mycol 2008, 12:1-7. 
57. Ullmann AJ, Cornely OA, Burchardt A, et al.: Pharmacokinetics, safety, and efficacy of posaconazole in patients with persistent febrile neutropenia or refractory invasive fungal infection. Antimicrob Agents Chemother 2006, 50:658-666.

58. Krishna G, Sansone-Parsons A, Martinho M, et al.: Posaconazole plasma concentrations in juvenile patients with invasive fungal infection. Antimicrob Agents Chemother 2007, 51:812-818.

59. Krishna G, Martinho M, Chandrasekar P, et al.: Pharmacokinetics of oral posaconazole in allogeneic hematopoietic stem cell transplant recipients with graft-versus-host disease. Pharmacotherapy 2007, 27:1627-1636.

60. Sun QN, Najvar LK, Bocanegra R, et al.: In vivo activity of posaconazole against Mucor spp. in an immunosuppressed-mouse model. Antimicrob Agents Chemother 2002, 46:2310-2312.

61. Rodriguez MM, Serena C, Marine M, et al.: Posaconazole combined with amphotericin $\mathrm{B}$, an effective therapy for a murine-disseminated infection caused by Rhizopus oryzae. Antimicrob Agents Chemother 2008, 52:3786-3788.

62. Ibrahim AS, Gebremariam T, Schwartz JA, et al.: Posaconazole mono- or combination therapy for murine mucormycosis. Antimicrob Agents Chemother 2009, 53:772-775.

63. Lekakis LJ, Lawson A, Prante J, et al.: Fatal rhizopus pneumonia in allogeneic stem cell transplant patients despite posaconazole prophylaxis: two cases and review of the literature. Biol Blood Marrow Transplant 2009, 15:991-995.

64. Mousset S, Bug G, Heinz WJ, et al.: Breakthrough zygomycosis on posaconazole prophylaxis after allogeneic stem cell transplantation. Transpl Infect Dis 2009 (Epub ahead of print).

65. Schlemmer F, Lagrange-Xelot M, Lacroix C, et al.: Breakthrough Rhizopus infection on posaconazole prophylaxis following allogeneic stem cell transplantation. Bone Marrow Transplant 2008, 42:551-552.

66. van Burik JA, Hare RS, Solomon HF, et al.: Posaconazole is effective as salvage therapy in zygomycosis: a retrospective summary of 91 cases. Clin Infect Dis 2006, 42:e61-e65.

67. Greenberg RN, Mullane K, van Burik JA, et al.: Posaconazole as salvage therapy for zygomycosis. Antimicrob Agents Chemother 2006, 50:126-133.

68. Ibrahim AS, Bowman JC, Avanessian V, et al.: Caspofungin inhibits Rhizopus oryzae 1,3-beta-D-glucan synthase, lowers burden in brain measured by quantitative PCR, and improves survival at a low but not a high dose during murine disseminated zygomycosis. Antimicrob Agents Chemother 2005, 49:721-727.

69. Spellberg B, Fu Y, Edwards JE Jr, Ibrahim AS: Combination therapy with amphotericin B lipid complex and caspofungin acetate of disseminated zygomycosis in diabetic ketoacidotic mice. Antimicrob Agents Chemother 2005, 49:830-832.

70. Ibrahim AS, Gebremariam T, Fu Y, et al.: Combination echinocandin-polyene treatment of murine mucormycosis. Antimicrob Agents Chemother 2008, 52:1556-1558.

71. Ibrahim AS, Edwards JE Jr, Bryant R, Spellberg B: Economic burden of mucormycosis in the United States: can a vaccine be cost-effective? Med Mycol 2009, 47:592-600.

72. Boelaert JR, Van Cutsem J, de Locht M, et al.: Deferoxamine augments growth and pathogenicity of Rhizopus, while hydroxypyridinone chelators have no effect. Kidney Int 1994, 45:667-671.

73. de Locht M, Boelaert JR, Schneider YJ: Iron uptake from ferrioxamine and from ferrirhizoferrin by germinating spores of Rhizopus microsporus. Biochem Pharmacol 1994, 47:1843-1850.

74. Ibrahim AS, Edwards JE Jr, Fu Y, Spellberg B: Deferiprone iron chelation as a novel therapy for experimental mucormycosis. J Antimicrob Chemother 2006, 58:1070-1073.

75. Ibrahim AS, Gebremariam T, Lin L, et al.: The high affinity iron permease is a key virulence factor required for Rhizopus oryzae pathogenesis. Mol Microbiol 2010 (Epub ahead of print).

76. •- Liu M, Spellberg B, Phan QT, et al.: The endothelial cell receptor GRP78 is required for mucormycosis pathogenesis in diabetic mice. J Clin Invest 2010, 120:1914-1924. This study elucidates a primary mechanism by which iron regulates host susceptibility to mucormycosis.

77. Cappellini MD: Iron-chelating therapy with the new oral agent ICL670 (Exjade). Best Pract Res Clin Haematol 2005, 18:289-298.

78. Piga A, Galanello R, Forni GL, et al.: Randomized phase II trial of deferasirox (Exjade, ICL670), a once-daily, orally-administered iron chelator, in comparison to deferoxamine in thalassemia patients with transfusional iron overload. Haematologica 2006, 91:873-880.

79. Miyazawa K, Ohyashiki K, Urabe A, et al.: A safety, pharmacokinetic and pharmacodynamic investigation of deferasirox (Exjade, ICL670) in patients with transfusion-dependent anemias and iron-overload: a phase I study in Japan. Int J Hematol 2008, 88:73-81.

80. Reed C, Ibrahim A, Edwards JE Jr, et al.: Deferasirox, an ironchelating agent, as salvage therapy for rhinocerebral mucormycosis. Antimicrob Agents Chemother 2006, 50:3968-3969.

81. Spellberg B, Andes D, Perez M, et al.: Safety and outcomes of open-label deferasirox iron chelation therapy for mucormycosis. Antimicrob Agents Chemother 2009, 53:3122-3125.

82. Vichinsky E: Clinical application of deferasirox: practical patient management. Am J Hematol 2007, 83:398-402.

83. Nick H, Wong A, Acklin P, et al.: ICL670A: preclinical profile. Adv Exp Med Biol 2002, 509:185-203.

84. Cappellini MD, Cohen A, Piga A, et al.: A phase 3 study of deferasirox (ICL670), a once-daily oral iron chelator, in patients with beta-thalassemia. Blood 2006, 107:3455-3462.

85. US Food and Drug Administration: Important information about Exjade (deferasirox) tablets for oral suspension (Novartis, 2007). Available at http://www.fda.gov/downloads/Safety/MedWatch/ SafetyInformation/SafetyAlertsforHumanMedicalProducts/ UCM154395.pdf. Accessed June 2010.

86. Ben-Ami R, Lewis RE, Tarrand J, et al.: Antifungal activity of colistin against mucorales species in vitro and in a murine model of Rhizopus oryzae pulmonary infection. Antimicrob Agents Chemother 2010, 54:484-490.

87. Gil-Lamaignere C, Simitsopoulou M, Roilides E, et al.: Interferon- gamma and granulocyte-macrophage colonystimulating factor augment the activity of polymorphonuclear leukocytes against medically important zygomycetes. J Infect Dis 2005, 191:1180-1187.

88. Abzug MJ, Walsh TJ: Interferon-gamma and colony-stimulating factors as adjuvant therapy for refractory fungal infections in children. Pediatr Infect Dis J 2004, 23:769-773.

89. Gonzalez CE, Couriel DR, Walsh TJ: Disseminated zygomycosis in a neutropenic patient: successful treatment with amphotericin B lipid complex and granulocyte colony-stimulating factor. Clin Infect Dis 1997, 24:192-196.

90. Kullberg BJ, Anaissie EJ: Cytokines as therapy for opportunistic fungal infections. Res Immunol 1998, 149:478-488; discussion 515.

91. Grigull L, Beilken A, Schmid H, et al.: Secondary prophylaxis of invasive fungal infections with combination antifungal therapy and G-CSF-mobilized granulocyte transfusions in three children with hematological malignancies. Support Care Cancer 2006, 14:783-786.

92. John BV, Chamilos G, Kontoyiannis DP: Hyperbaric oxygen as an adjunctive treatment for zygomycosis. Clin Microbiol Infect 2005, 11:515-517.

93. Busca A, Marmont F, Locatelli F, et al.: Combined antifungal therapy, iron chelation and surgical resection as treatment of hepatic zygomycosis in a patient with haematological malignancy. Mycoses 2010, 53:275-278.

94. Rodriguez MM, Pastor FJ, Calvo E, et al.: Correlation of in vitro activity, serum levels, and in vivo efficacy of posaconazole against Rhizopus microsporus in a murine disseminated infection. Antimicrob Agents Chemother 2009, 53:5022-5025. 